\title{
The known molecules involved in MSC homing and migration
}

\author{
Haniyeh Ghaffari-Nazari \\ Immunogenetic and Cell Culture Department, Immunology Research Center, School of Medicine, Mashhad University of Medical Sciences, Mashhad, Iran
}

\begin{abstract}
Mesenchymal stem cells (MSCs) are multipotent adult stem cells and known as promising candidates for use in cell-based therapy. Following systemic administration, MSCs have been shown to accumulate at sites of inflammation and injured tissue. There are several factors regarding the MSC trafficking and homing in MSC therapy. This review describes the known molecules in MSC migration and homing.
\end{abstract}

\begin{abstract}
Abbreviations: VLA-4: Very Late Antigen-4; MSCs: Mesenchymal Stem Cells; SSEA: Stage Specific Embryonic Antigen; PDGF- $\alpha$ : Platelet-Derived Growth Factor Receptor- Alpha; TWIST: Twist-Related Protein 1; HLA-DR: Human Leukocyte Antigen Class II; ICAM-1: Intercellular Adhesion Molecule 1; VCAM-1: Vascular Cell Adhesion Molecule 1; ALCAM: Activated Leukocyte Cell Adhesion Molecule; MCP-1: Monocyte Chemoattractant Protein-1; MIP-1a: Macrophage Inflammatory Protein-1 Alpha; RT-PCR: Real-Time Polymerase Chain Reaction (Real-Time PCR); BM: Bone Marrow; UC: Umbilical Cord; SDF-1: Stromal Cell-Derived Factor-1; TNF- $\alpha$ : Tumor Necrosis Factor- Alpha; IGF-1: Insulin-Like Growth Factor-1; PI3K/Akt: Phosphatidylinositol 3-Kinase/Protein Kinase B; SCF: Stem Cell Factor; HGF: Hepatocyte Growth Factor; FlT3-l: FMS- Like Tyrosine Kinase 3-Ligand; MMP: Matrix Metalloproteinase; MT1-MMP: MembraneType-1 Matrix Metalloproteinase; siRNA: Small Interfering RNA; TIMP-3: Tissue Inhibitor of Metalloproteinases-3; PDGFR- $\alpha$ : PlateletDerived Growth Factor Receptor- Alpha; PIGF: Placenta Growth Factor; TGF- $\alpha$ : Transforming Growth Factor- Alpha; IL-1: Interleukin-1.
\end{abstract}

\section{Introduction}

Mesenchymal stem cells are non-hematopoietic stem cell population that was first characterized by Friedenstein and colleagues [1]. MSCs population approximately were estimated 1 in 10,000 nucleated cells in bone marrow [2]. MSCs have a supportive function for the haematopoiesis in the bone marrow and prepare a niche for maturation of hematopoietic progenitor cells [3]. MSCs are identified by the expression of a number of surface markers including, CD13, CD54, CD105 (SH2 or endoglin), CD73 (SH3 or SH4), and CD166, CD44, CD29, and CD90 (Thy-1). MSCs do not express hematopoietic surface markers CD45, CD34, CD14, CD11b, CD79 $\alpha$, and CD19. They also do not express the costimulatory molecules CD80, CD86, or CD40 [4]. Stro-1[5], CD271(low-affinity nerve growth factor receptor) [6], stage specific embryonic antigen-4 (SSEA-4) [7], CD146 [8], CD49a [9], CD106, and leptin receptor [10] are cell surface antigens that have been reported to enrich homogeneous MSCs. It is shown that MSC could be enriched through specific markers, for example, they are enriched from peripheral and the UC blood through selecting CD133, or from BM through selecting stage-specific embryonic antigen (SSEA)-1, SSEA-4 [11]. Analysis of cell surface biomarkers revealed that MSC with strong self-renewal capability preferentially express Stro- 1 and PDGF- $\alpha$ (platelet-derived growth factor receptor alpha), and they also expressed the highest level of TWIST-1 and DERMO-1 mRNA transcripts [12]. The Mesenchymal and Tissue Stem Cell Committee of the International Society for Cellular Therapy (ISCT) provided a set of standards to define MSCs include: (a) Remain plastic-adherent under standard culture conditions; (b) Express CD105, CD73, and CD90, and lack expression of CD45, CD34, CD14 or CD11b, CD79a or CD19, and HLA-DR; (c) Differentiate into osteoblasts, adipocytes, and chondrocytes in vitro [13].

\section{MSCs migration and homing}

MSCs have been shown to mobilize into peripheral blood and migrate to other tissues in response to injuries and various types of diseases such as acute burns, skeletal muscle injury, chronic hypoxia, inflammation, heart diseases, neurological disorders, rheumatoid arthritis, graft-versus-host disease and etc $[14,15]$. Although there are few studies about the mechanisms of MSC homing, several agents have suggested the homing mechanisms (Table 1).

\section{Mechanism of MSC migration and homing}

\section{Role of Adhesion molecule interactions in MSC homing}

MSCs movement in the bloodstream and transendothelial migration is one of the most important stages of homing. It is assumed that MSCs utilize the same mechanism as leukocyte migration to move into the bloodstream. Adhesion molecules are important for MSC trafficking. Integrin blocking, and knockout studies have supported that MSCs migration is related to their interactions with integrins and selectins. MSCs express adhesion molecules, including: integrins, selectins, and

${ }^{\star}$ Correspondence to: Haniyeh Ghaffari-Nazari, Immunogenetic and Cell Culture Department, Immunology Research Center, School of Medicine, Mashhad University of Medical Sciences, Mashhad, Iran, E-mail: nazarih931@mums.ac.ir; haniye.ghafari66@gmail.com

Key words: Mesenchymal stem cells; homing; migration

Received: May 15, 2018; Accepted: May 28, 2018; Published: June 05, 2018 
Table 1. The molecules involved in MSC migration and homing

\begin{tabular}{|l|l|l|l|}
\hline & Molecules & Migration stage & References \\
\hline Adhesion molecules & VLA-4, VCAM-1, ICAM-1, P-selectin & Rolling and transendothelial migration & {$[16,17]$} \\
\hline Chemokines/receptors & IL-8, MIP-1 $\alpha$, MCP-1, SDF-1 & Chemotaxis and traffic & {$[18-21]$} \\
\hline CCR $1 / 2 / 4 / 6 / 8 / 9$, CXCR1/2/3/4/5/6 & TGF- $\beta$, TNF- $\alpha$, IL-1 $\beta$, IL-6, IL-3, FlT3-L, & Chemotaxis and traffic & [22-25] \\
\hline Matrix metalloproteinases & IGF-1, SCF, HGF, PlGF, PDGF & Invasion & {$[26]$} \\
\hline
\end{tabular}

chemokine receptors, which are involved in the tethering, rolling, adhesion, and transmigration of leukocytes from the bloodstream into tissues. MSCs express integrin molecules, such as $\alpha 1, \alpha 2, \alpha 3, \alpha 4$, $\alpha 5, \alpha v, \beta 1, \beta 3$, and $\beta 4$. MSCs also express other adhesion molecules, including: VCAM-1, ICAM-1, ICAM-3, CD166 (ALCAM), endoglin/ CD105. It has been estimated that VLA-4 is expressed in approximately $50 \%$ of hMSCs $[1,16]$. Although the study has shown that MSCs and leukocytes likely utilize some similar molecules and mechanisms for transmigration, there are some specific differences between MSCs and leukocytes in employing adhesion molecules. Studies have revealed $\beta 1$ integrins possess a crucial role in MSC rolling and attachment, but many of $\beta 2$ integrins are not expressed on MSC surface [16,17]. Some studies have shown attachment of MSC to endothelial layer has resulted from $\mathrm{P}$ selectin interaction. On the other hand, it has been shown that MSC do not express PSGL-1 and an alternative ligand CD24, and their endothelial interaction is dependent on P-selectin. It is assumed that MSC might express new carbohydrate ligands to bind P-selectin expressed on endothelial cell. Also, data have shown E- selectin, and L- selectin, which function in the initial leukocyte rolling stage, do not or barely express on MSCs and their contributions to MSC trafficking are not remarkable in comparison with P- selectin [16]. It has been reported rolling mediate due to VLA-4/VCAM-1 interactions and they make firm adhesion of MSC to endothelial cells. To MSCs express VLA-4and VCAM-1 adhesion molecules and it has been shown that VLA-4 and VCAM- 1 are important receptors to transendothelial MSCs migration. Observations have shown anti-VCAM-1 antibody reduced attachment of rat MSC to endothelial cells [17]. Steingen has reported that MSC could transmigrate through nonactivated endothelium via VLA-4 /VCAM-1 and they tend to integrate with the endothelial layer rather than undergoing complete diapedesis. Among the integrins family, $\alpha 4 \beta 1$ integrin, which is a cell surface heterodimer and mediates cell-cell and cell- extracellular matrix contact, plays a key role in adhesion, migration and chemotaxis. Since MSC transendothelial migration is not completely blocked by the anti-VLA4 antibody and anti-VCAM1 antibody, it is suggested other integrins are involved in the MSC migration process [18]. The aforementioned data show that different adhesion molecules are expressed by MSC and involved in MSC migration and homing.

\section{Role of Chemokine and Chemokine Receptors in MSC homing}

Although integrins and selectins play role in the transmigration of MSC, chemokines released from tissues and endothelial cells could promote activation of ligands that are involved in attachment, migration, chemotaxis and maintenance of MSC in target tissues. It has been shown that MSCs are able to migrate into inflamed tissues in response to chemokines and chemokine receptor signals that are induced under inflammatory conditions [19]. MSCs express a wide range of chemokine and chemokine receptors that have been shown to play a role in MSC homing. Some reports have shown expression of chemokine receptors; including, CCR1, CCR2, CCR4, CCR6, CCR7, CCR8, CCR9, CCR10, CXCR1, CXCR2, CXCR3, CXCR4, CXCR5, CXCR6 on MSCs and have reported functional roles of some of these chemokine receptors in MSCs migration [20-23]. CXCR1, CXCR2, CXCR4, CCR1, CCR2, IL-8, MIP-1 $\alpha$, MCP-1 are involved in MSCs migration to damaged tissue [24]. Recent studies showed that $43-70 \%$ of MSCs expressed functional CCR1, CCR7, CCR9, CXCR4, CXCR5, and CXCR6 $[20,25]$. Using RT-PCR the data showed that mRNA expression of CCR1, CXCR4, CCR7, CXCR6 and CXCR3 is low in adipose tissue-derived MSCs and nearly undetectable in most BMMSCs [19]. The majority of these studies have detected expression of chemokine receptors by flow cytometry analysis, real-time polymerase chain reaction, immunohistochemistry, and chemotaxis assay. Ponte and colleagues [26] demonstrated TNF- $\alpha$ could increase expression of CCR2, CCR3, and CCR4 but CXCR4 expression was not affected. The expression of CXCR4 plays a critical role in migration and homing of MSCs. Wynn and colleagues have reported less than $1 \%$ of MSCs express CXCR4 on the cell membrane, although intracellular expression of CXCR4 (83-98\%) was noted [27]. Pre-treatment of BM-MSC with TNF- $\alpha$ significantly increases CXCR4 expression and the capacity of MSC migration, especially in response to SDF-1 [28]. It is known that IGF-1 not only has individually induced MSC migration, but also it has caused CXCR4 upregulation. Moreover, IGF-1 could induce MSC migration in response to SDF-1. This study also indicated that IGF-1 increases MSC migration through CXCR4 chemokine receptor signaling in a PI3/Akt dependent manner [29]. Also, treatment of BM-MSC with some cytokines such as, FlT3-L, SCF, IL-6, HGF and IL-3 has significantly upregulated intracellular and extracellular expression levels of CXCR4 [30]. Studies have shown SDF-1/CXCR4 axis performs the important role in migration of MSC to the bone marrow. CXCR4 responses to SDF-1 in a dose dependent manner [31]. Su et al. [32] also indicated that the expression level of SDF-1a controls the homing of MSCs. Therefore, it is likely that under chemokine stimulation condition intracellular CXCR4 translocates to the cell surface and contributes to the migration of MSC to target site.

The MCP-1 expression is upregulated at the inflammation site and known as homing chemokine. Previous studies indicated MCP1 contributed to monocyte recruitment to inflammation site. MSCs express CCR2, which is a MCP-1 receptor [33]. Transwell migration assay showed MCP-1 induced migration of mouse and human bone marrow derived MSCs [34,35]. In vivo studies have shown the antiCCR2 antibody and blockage of downstream CCR2 signalling pathway could prohibit MSCs migration [36]. On the other hand, Ring et al. [20] have reported human BM-MSC do not significantly migrate in response to MCP-1 gradient. MIP-1a is the other chemokine which is possible to play role in MSC migration. MIP-1 $\alpha$ induces proinflammatory immune cells recruitment to the inflammation site and regulates their transendothelial migration [37]. CCR1 is known as a MIP-1a receptor and is expressed on MSC surface [25]. The transwell migration assay has shown the presence of MIP-1a induces increased migration in cultured BM-MSC [35]. It is suggested MIP1 $\alpha$ as a soluble factor might be involved in controlling of the MSCs homing process. It is shown IL-8 upregulation in the injured tissue sites may be causing MSC migration to the injured site. CXCR1/CXCR2 are IL- 8 ligands on the MSC surface and MSC chemotactic response to an IL-8 has been demonstrated 
dose-dependent [20]. According to study numerous chemokines play role in induction of MSC migration, but the characterization involved mechanisms of MSC homing need further in vitro and in vivo studies. Different groups also reported that MSCs express a variety of chemokine receptors that could affect MSC homing to different tissue to facilitate tissue repair or reduce inflammation. For example, it has been suggested CCR9, and CCR1 could help MSC to enter the intestine and inflamed tissues, such as joint or brain in rheumatoid arthritis or multiple sclerosis, Respectively [1].

\section{Role of Matrix metalloproteinases in MSC homing}

MMPs are a zinc-dependent proteolytic enzyme family regulating ECM (extracellular matrix) degradation. Different MMPs and their signalling pathways have been shown to affect differentiation, migration, angiogenesis, and proliferation of MSCs. Migration and recruitment of expanded MSCs to damaged tissue are facilitated through expression of CXCR4, MMP-2 and MT1-MMP [38]. The MMP-2 expression is associated with MSCs transendothelial migration, although it is shown the increasing MSCs culture confluency diminished MSCs transendothelial migration through the inhibition of MMP-2 siRNA and the increase in TIMP-3 expression [39].

\section{Role of Cytokines and growth factors in MSC homing}

The active role of IL-6, PDGF, PDGFR- $\alpha$ (platelet-derived growth factor receptor $\alpha$ ), PDGFR- $\beta$, PlGF (placenta growth factor), vascular endothelial growth factor receptor 1 (Flt-1) and IGF-1 has been known in the migration of BM-MSCs [24]. Several studies showed that PDGFRs are highly expressed on the BM-MSC surface and PDGF induces BM-MSC migration. The transwell migration assay has shown, PDGF is a more potent MSC chemoattractant cytokine than SDF-1 and MCP-1 [40]. Inflammatory cytokines, including; TGF- $\alpha$, IL-1 $\beta$ and TNF- $\alpha$ stimulate MMP production by the MSCs and result in induction of potent chemotactic migration through the extracellular Matrix [41].

\section{Conclusion}

It is well known that MSCs have a capacity to migrate and home in injured and inflamed tissues. Different molecules were demonstrated to play a role in MSC migration and homing, but the exact mechanism of homing is still unclear. Understanding how MSCs migrate and home into target tissues could be improve future MSC-derived therapies.

\section{References}

1. Chamberlain G, Fox J, Ashton B, Middleton J (2007) Concise review: mesenchymal stem cells: their phenotype, differentiation capacity, immunological features, and potential for homing. Stem cells 25: 2739-49. [Crossref]

2. Chen X, Armstrong MA, Li G (2006) Mesenchymal stem cells in immunoregulation. Immunol Cell Biol 84: 413-421. [Crossref]

3. Aqmasheh S, Shamsasanjan K, Akbarzadehlaleh P, Pashoutan Sarvar D, Timari H (2017) Effects of Mesenchymal Stem Cell Derivatives on Hematopoiesis and Hematopoietic Stem Cells. Adv Pharm Bull 7: 165. [Crossref]

4. Boxall SA, Jones E (2012) Markers for characterization of bone marrow multipotential stromal cells. Stem Cells Int 2012: 975871. [Crossref]

5. Simmons PJ, Torok-Storb B (1991) Identification of stromal cell precursors in human bone marrow by a novel monoclonal antibody, STRO-1. Blood 78: 55-62. [Crossref]

6. Battula VL, Treml S, Bareiss PM, Gieseke F, Roelofs H, et al. (2009) Isolation of functionally distinct mesenchymal stem cell subsets using antibodies against CD56, CD271, and mesenchymal stem cell antigen-1. Haematologica 94: 173-184. [Crossref]

7. Gang EJ, Bosnakovski D, Figueiredo CA, Visser JW, Perlingeiro RC (2007) SSEA4 identifies mesenchymal stem cells from bone marrow. Blood 109: 1743-1751. [Crossref]
8. Tormin A, Li O, Brune JC, Walsh S, Schutz B, et al. (2011) CD146 expression on primary nonhematopoietic bone marrow stem cells is correlated with in situ localization. Blood 117: 5067-77. [Crossref]

9. Rider DA, Nalathamby T, Nurcombe V, Cool SM (2007) Selection using the alpha-1 integrin (CD49a) enhances the multipotentiality of the mesenchymal stem cell population from heterogeneous bone marrow stromal cells. J Mol Histol 38: 449-58. [Crossref]

10. Zhou BO, Yue R, Murphy MM, Peyer JG, Morrison SJ (2014) Leptin-receptorexpressing mesenchymal stromal cells represent the main source of bone formed by adult bone marrow. Cell Stem Cell 15: 154-68. [Crossref]

11. Lv FJ, Tuan RS, Cheung KM, Leung VY (2014) Concise review: the surface markers and identity of human mesenchymal stem cells. Stem Cells 32: 1408-1419. [Crossref]

12. Samsonraj RM, Rai B, Sathiyanathan P, Puan KJ, Rötzschke O et al. (2015) Establishing criteria for human mesenchymal stem cell potency. Stem Cells 33: 18781891. [Crossref]

13. Wuchter P, Bieback K, Schrezenmeier H, Bornhäuser M, Müller LP, et al. (2015) Standardization of Good Manufacturing Practice-compliant production of bone marrow-derived human mesenchymal stromal cells for immunotherapeutic applications. Cytotherapy 17: 128-39. [Crossref]

14. Si YL, Zhao YL, Hao HJ, Fu XB, Han WD (2011) MSCs: biological characteristics, clinical applications and their outstanding concerns. Ageing Res Rev 10: 93-103. [Crossref]

15. Choi JR, Yong KW, Safwani WKZ (2017) Effect of hypoxia on human adipose-derived mesenchymal stem cells and its potential clinical applications. Cell Mol Life Sci 74 2587-600. [Crossref]

16. Rüster B, Göttig S, Ludwig RJ, Bistrian R, Müller S, et al. (2006) Mesenchymal stem cells display coordinated rolling and adhesion behavior on endothelial cells. Blood 108 3938-3944. [Crossref]

17. Ip JE, Wu Y, Huang J, Zhang L, Pratt RE, et al. (2007) Mesenchymal stem cells use integrin $\beta 1$ not $\mathrm{CXC}$ chemokine receptor 4 for myocardial migration and engraftment. Mol Biol Cell 18: 2873-82. [Crossref]

18. Steingen C, Brenig F, Baumgartner L, Schmidt J, Schmidt A, et al. (2008) Characterization of key mechanisms in transmigration and invasion of mesenchymal stem cells. J Mol Cell Cardiol 44: 1072-1084. [Crossref]

19. Ahmadian Kia N, Bahrami AR, Ebrahimi M, Matin MM, Neshati Z, et al. (2011) Comparative analysis of chemokine receptor's expression in mesenchymal stem cells derived from human bone marrow and adipose tissue. J Mol Neurosci 44: 178-85. [Crossref]

20. Ringe J, Strassburg S, Neumann K, Endres M, Notter M, et al. (2007) Towards in situ tissue repair: human mesenchymal stem cells express chemokine receptors CXCR1, CXCR2 and CCR2, and migrate upon stimulation with CXCL8 but not CCL2. J Cell Biochem 101: 135-46. [Crossref]

21. Von Lüttichau I, Notohamiprodjo M, Wechselberger A, Peters C, Henger A, et al (2005) Human adult CD34- progenitor cells functionally express the chemokine receptors CCR1, CCR4, CCR7, CXCR5, and CCR10 but not CXCR4. Stem Cells Dev 14: 329-336. [Crossref]

22. Sordi V, Malosio ML, Marchesi F, Mercalli A, Melzi R, et al. (2005) Bone marrow mesenchymal stem cells express a restricted set of functionally active chemokine receptors capable of promoting migration to pancreatic islets. Blood 106: 419-427. [Crossref]

23. Honczarenko M, Le Y, Swierkowski M, Ghiran I, Glodek AM, et al. (2006) Human bone marrow stromal cells express a distinct set of biologically functional chemokine receptors. Stem Cells 24: 1030-41. [Crossref]

24. Eseonu OI, De Bari C (2015) Homing of mesenchymal stem cells: mechanistic or stochastic? Implications for targeted delivery in arthritis. Rheumatology (Oxford) 54: 210-8. [Crossref]

25. Sordi V, Malosio ML, Marchesi F, Mercalli A, Melzi R, et al. (2005) Bone marrow mesenchymal stem cells express a restricted set of functionally active chemokine receptors capable of promoting migration to pancreatic islets. Blood 106: 419-427. [Crossref]

26. Ponte AL, Marais E, Gallay N, Langonne A, Delorme B, et al. (2007) The in vitro migration capacity of human bone marrow mesenchymal stem cells: comparison of chemokine and growth factor chemotactic activities. Stem cells 25: 1737-45. [Crossref]

27. Wynn RF, Hart CA, Corradi-Perini C, O’Neill L, Evans CA, et al. (2004) A smal proportion of mesenchymal stem cells strongly expresses functionally active CXCR4 receptor capable of promoting migration to bone marrow. Blood 104: 2643-2645. [Crossref] 
28. Kholodenko IV, Konieva AA, Kholodenko RV, Yarygin KN (2013) Molecular mechanisms of migration and homing of intravenously transplanted mesenchymal stem cells. J Regen Med Tissue Eng 2:4.

29. Li Y, Yu X, Lin S, Li X, Zhang S, et al. (2007) Insulin-like growth factor 1 enhances the migratory capacity of mesenchymal stem cells. Biochem Biophys Res Commun 356 780-784. [Crossref]

30. Shi M, Li J, Liao L, Chen B, Li B, et al. (2007) Regulation of CXCR4 expression in human mesenchymal stem cells by cytokine treatment: role in homing efficiency in NOD/SCID mice. Haematologica 92: 897-904. [Crossref]

31. Kitaori T, Ito H, Schwarz EM, Tsutsumi R, Yoshitomi H, et al. (2009) Stromal cellderived factor $1 / \mathrm{CXCR} 4$ signaling is critical for the recruitment of mesenchymal stem cells to the fracture site during skeletal repair in a mouse model. Arthritis Rheum 60: 813-23. [Crossref]

32. Su G, Liu L, Yang L, Mu Y, Guan L (2017) Homing of endogenous bone marrow mesenchymal stem cells to rat infarcted myocardium via ultrasound-mediated recombinant SDF-1a adenovirus in microbubbles. Oncotarget 9: 477-487. [Crossref]

33. Eseonu OI, De Bari C (2015) Homing of mesenchymal stem cells: mechanistic or stochastic? Implications for targeted delivery in arthritis. Rheumatology (Oxford) 54: 210-218. [Crossref]

34. Dwyer RM, Potter-Beirne SM, Harrington KA, Lowery AJ, Hennessy E, et al (2007) Monocyte chemotactic protein-1 secreted by primary breast tumors stimulates migration of mesenchymal stem cells. Clin Cancer Res 13: 5020-7. [Crossref]
35. Boomsma RA, Geenen DL (2012) Mesenchymal stem cells secrete multiple cytokines that promote angiogenesis and have contrasting effects on chemotaxis and apoptosis. PLoS One 7: e35685. [Crossref]

36. Belema-Bedada F, Uchida S, Martire A, Kostin S, Braun T (2008) Efficient homing of multipotent adult mesenchymal stem cells depends on FROUNT-mediated clustering of CCR2. Cell stem cell 2: 566-75. [Crossref]

37. Maurer M, von Stebut E (2004) Macrophage inflammatory protein-1. Int J Biochem Cell Biol 36: 1882-1886. [Crossref]

38. Almalki SG, Agrawal DK (2016) Effects of matrix metalloproteinases on the fate of mesenchymal stem cells. Stem Cell Res Ther 7: 129. [Crossref]

39. De Becker A, Van Hummelen P, Bakkus M, Broek IV, De Wever J, et al. (2007) Migration of culture-expanded human mesenchymal stem cells through bone marrow endothelium is regulated by matrix metalloproteinase- 2 and tissue inhibitor of metalloproteinase-3. Haematologica 92: 440-9. [Crossref]

40. Lee JM, Kim B-S, Lee H, Im GI (2012) In vivo tracking of mesechymal stem cells using fluorescent nanoparticles in an osteochondral repair model. Mol Ther 20: 143442. [Crossref]

41. Sohni A, Verfaillie CM (2013) Mesenchymal stem cells migration homing and tracking. Stem Cells Int 2013: 130763. [Crossref]

Copyright: $\odot 2018$ Ghaffari-Nazari H. This is an open-access article distributed under the terms of the Creative Commons Attribution License, which permits unrestricted use, distribution, and reproduction in any medium, provided the original author and source are credited. 